pointed out fairly, and in precise unequivocal terms. The proposition, consciously or unconsciously affirmed by "Spectator" in his last letter-the proposition which he helps to establish by his quotation from Hazlitt, viz., that beings are to be considered "moral and accountable" in the ratio of their susceptibility to " moral motives," is one to the truth of which Mr. Sampson will, no doubt, cheerfully assent. The question still remains open, viz., Are all men equally susceptible to the influence of moral motives? I pass by your correspondent's statement regarding "the proper province of phrenology," being utterly at a loss to reconcile it with even a moderate knowledge on his part of the elementary principles of the science in which he professes to put faith. Phreno$\operatorname{logy}$, as explained by Gall, Spurzheim, Combe, and others, teaches us, 1st, that the brain is the organ of the mind; 2nd, that the brain is a congeries of organs; 3rd, that, cateris paribus, size is the measure of power; Ath, that susceptibility and activity depend upon the temperament, the influence of which extends alike to all the cerebral organs. Phrenology teaches us, that men with heads like Melancthon, experience lively emotions of a moral character, and that such men feel strongly impelled to do that which is right. That men with heads like Hare or Burke may recognise intellectually the difference between right and wrong; that is, they may perceive that a particular action is of a class called wrong by the world, that another is of a class called right by the world; but that the sensible appreciation of the morality of the act, the feeling or sentiment which can alone furnish a restraining motive, is in them extremely weak, and liable to be overborne by strong temptation. The question evidently suggested to Mr. Sampson's mind by this doctrine, is not-What is then the degree of such a man's moral guilt in the sight of his Maker? Such a question would be at once impious and absurd. None but the "Searcher of all hearts" himself can determine what is due from each of his creatures to $\mathrm{Mim}$; but rather this, 'To what extent are we on earth justified in taking vengeance upon our fellow-man for "crimes" committed by him? Mr. Sampson may be right, or he may be wrong: one thing is clear, he is in possession of the field of action; and so he is likely to remain, until " a stronger than he" shall overcome him with the weapons of fact and argument which he employs so ably. I am, Sir, your faithful servant,

R. W. Heurthey.

萿ensington, May 30, 1842.

\section{NOTE FROM DR. DICK.}

To the Editor of The Lancet.

SIR,-I must make a thousand apologies to you and your readers, for returning once more to that question of phrenology, vexata
(I may surely well add) usque ad nauseam; but justice to myself requires me to state, explicitly and once for all, that (contrary to what "Spectator" supposes) I am a phrenologist! I believe, and in my late papers have repeatedly asserted, the brain to be the organ of the mind; which opinion or admis. sion regularly constitutes me a phrenologist. It is true, indeed, that my phrenological creed (sceptic as I must appear to the orthodox Messrs. Sampson and Combe!) consists of but a single, and that, too, a most general doctrine; yet for going beyond which I de. liberately maintain we have no data. That single doctrine, which I purposely clothe in the most general terms possible, is, that there seems to exist a relation between the anterior part of the brain and the intellect. What I consider the amazing credulity of Messis. Combe, Sampson, \&c., a credulity which partly surprises, partly amuses me, will by no means prevent me from avowing myself a phrenologist in my way, which it will be perceived is widely different from, though as real as theirs. I may add my firm and solemn conviction, that until it be generally understood, as it long since ought to have been, that sound and rational phrenolooy and Mr. Combe's theories, are things just as opposite as light and night, an eternal hos. tility will ex ist to the former, in many or in most intelligent minds.

Another grand tenet of mine, of which I hope and believe most of your readers are convinced, is, that so long as a man is intellectually sane he is morally responsible. The utopian (or not to misapply a word of pleas. ing import) the wildly chimerical character of the contrary view, will ever be a safe antidote to the dangerousness of it. I am, $\mathrm{Bir}$, your obedient servant,

London, May, 1842.

Robert Dick, M.D.

\section{MEDICAL ASSOCIATIONS} FOR THE

\section{PREVENTION OF ILLEGAL PRACTICE.}

\section{To the Editor of THE LANCET.}

Sir,-I beg leave, through the medium of your widely-circulated $\mathbf{J}$ oumal, to call upon the legally-authorised practitioners of medicine in this metropolis to form district as50. ciations for the suppression of illegal practice. It is notorious that such is carried on to an enormous extent; but under the influ. ence of the feeling that what is the business of everybody is the business of nobodr, nothing is done: some cases, few and far between, are exposed, but the great mass of the evil is allowed to exist undisturbed. It is certainly by no means a pleasant thing for an individual to appear as an informer, but the odium would not be thus felt if the matter 